Britain is lagging behind other European countries and some American states in detecting HIV positive pregnant women. ${ }^{4}$ Furthermore, even in locations such as ours, where current Department of Health recommendations are being implemented, uptake is disappointingly low. As a matter of urgency, multidisciplinary research needs to be directed towards discovering why pregnant women seem to feel that the social consequences of being identified as HIV positive outweigh the advantages of high quality management for mother and baby. In the meantime the Department of Health should strongly support the recommendations of the Intercollegiate Working Party for Enhancing Voluntary Confidential HIV Testing in Pregnancy, and consideration should be given to implementing an opt-out approach to HIV testing, as approved by the working party of the Institute of Medical Ethics in 1990.5

We thank colleagues involved in the European study on antenatal HIV testing-policies and procedures (EU grant SOC 95200587 05F202) for their help.

Contributors: Each of the authors has been involved in the ongoing investigations of antenatal HIV testing at Guy's and St Thomas'Trust and participated in the design of the 1996 uptake study. TAD with the assistance of JK carried out that study, with statistical analysis being coordinated by CV and CDAW. ILC and JEB collated and analysed the 1991-6 uptake data. The paper was written jointly by ILC and JEB with input from the other authors.
Intention to take HIV test before and after prebooking discussion. Values are numbers (percentages)*

\begin{tabular}{|c|c|c|c|c|c|}
\hline & & \multicolumn{4}{|c|}{ After discussion with midwife } \\
\hline & & Yes & No & Don't know & Total \\
\hline \multirow{4}{*}{$\begin{array}{l}\text { Before } \\
\text { discussion } \\
\text { with } \\
\text { midwife }\end{array}$} & Yes & $206(64)$ & $70(22)$ & $44(14)$ & 320 \\
\hline & No & $13(5)$ & $238(90)$ & $12(4)$ & 283 \\
\hline & Don't know & $51(26)$ & $90(46)$ & $54(28)$ & 195 \\
\hline & Total & $270(35)$ & $398(51)$ & $110(14)$ & 778 \\
\hline
\end{tabular}

*Some questionnaires were not completed fully.

Funding: Lambeth, Southwark, and Lewisham Health Authority.

Conflict of interest: None.

1 Public Health Laboratory Service. Unlinked anonymous HIV prevalence monitoring programme: England and Wales. Survey of antenatal clinic monttoring programme: England and Wales. Survey of

2 Chrystie IL, Palmer SJ, Kenney A, Banatvala JE. HIV seroprevalence among women attending antenatal clinics in London. Lancet 1991;339:364.

3 Unlinked Anonymous Surveys Steering Group. Unlinked anomymous HIV seroprevalence momitoring programme. London: Department of Health, 1996.

4 Westmorland T. Workshop on political, ethical, legal, and human rights issues confronting implementation of global strategy. International conference on global strategies for the prevention of HIV from mothers to infants. Washington, DC: American Society for Microbiology, Office of AIDS Research, 1997.

5 Boyd KM. HIV infection: the ethics of anonymised testing and of testing pregnant women. Institute of Medical ethics; working party report. J Med Ethics 1990;16:173-8.

(Accepted 10 December 1997)

\title{
Late diagnosis of paediatric HIV infection in south west London
}

\author{
M P Richardson, M Sharland
}

The family clinic at St George's Hospital provides care for HIV positive children throughout south west London. We are increasingly concerned about the late presentation of many children. This is particularly worrying because in 1992 the Department of Health recommended that all women attending antenatal clinics in areas of higher prevalence (such as Greater London) should be offered an HIV test. ${ }^{1}$ If these guidelines had been effective we would have expected most HIV infected children to be recognised in the perinatal period. To assess the scale of the problem we reviewed the method of presentation of vertically infected children in our area.

\section{Patients, methods, and results}

We studied the hospital notes of all children who attended our clinic between 1986 and 1996 and identified 48 children with vertically acquired HIV infection. (None of these children had risk factors for horizontally acquired HIV infection.)

Presentation was defined as perinatal if the child was referred at, or around, the time of birth; asymptomatic if the child was referred after the identification of another infected family member or after the incidental finding of signs suggestive of HIV infection; and symptomatic if the child's initial complaint was a clinical manifestation of HIV infection. Severity of symptoms and immunological status at diagnosis were staged according to the revised CDC classification. ${ }^{2}$ To determine the effect of the Department of Health guidelines, we compared children born before or during $1992(n=24)$ with those born after $1992(n=24)$.

Age at presentation for the whole group ranged from birth to 9 years (median 19 months). The table shows that a significantly higher proportion of children were born in London after $1992\left(5 / 24 v 17 / 24 ; \chi^{2}=\right.$ $2.1, \mathrm{P}<0.001)$. The mode of presentation and disease stage at diagnosis were similar in the two groups $\left(\chi^{2}\right.$ for trend $<1.0, \mathrm{P}>0.2)$. Twenty-three children (48\%; $95 \%$ confidence interval $34 \%$ to $62 \%$ ) presented with infections and $16(33 \% ; 20 \%$ to $46 \%)$ presented with manifestations of organ involvement such as lymphadenopathy and parotitis. On examination, 31 children (65\%; $52 \%$ to $78 \%$ ) had signs of organ involvement.

\section{Comment}

In our area the Department of Health guidelines on antenatal testing have had no effect on the method of presentation of paediatric HIV infection. Since the guidelines were issued in 1992, the mother's HIV infection had been detected by antenatal testing in only one $(6 \%)$ of the 17 children born in London.
See editorial by Mercey

Paediatric Infectious Diseases Unit, St George's Hospital, London SW17 0QT M P Richardson, senior registrar M Sharland, consultant

Correspondence to: Dr Richardson mrichard@sghms.ac.uk

BMJ 1998;316:271-2 
Patients' characteristics, method of presentation, and stage of disease at diagnosis of 48 children with vertically acquired HIV infection

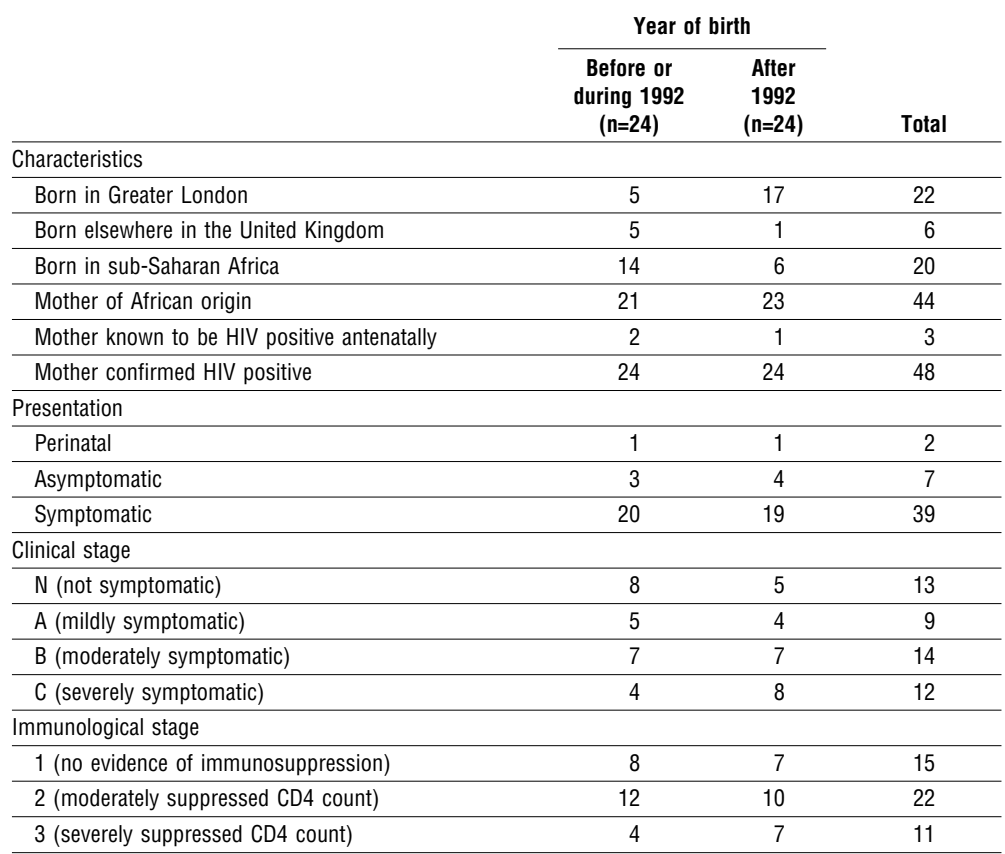

Although poor, this detection rate is no worse than that calculated from unlinked anonymous testing in London and south east England as a whole. ${ }^{3}$ In 1995 the estimated proportion of HIV positive women giving birth who were aware of their diagnosis was $13 \%$. The proportion detected by antenatal testing was $4.8 \%$. These figures are particularly disappointing because antenatal diagnosis allows the use of perinatal antiretroviral therapy, an intervention that dramatically reduces the transmission of HIV from mother to child. ${ }^{4}$ In addition, HIV positive mothers can be advised to avoid breastfeeding as this will also reduce the risk of the infant being infected.

Most HIV positive children in this study were diagnosed after the first year of life. Most presented with symptomatic disease, usually in the form of repeated or opportunistic infections, but signs of organ involvement (such as lymphadenopathy, parotitis, and hepatosplenomegaly) were identified in two thirds of the children. Prospective studies have shown that $80 \%$ of vertically infected children show such signs during infancy. ${ }^{5}$ Wider recognition of these manifestations, together with the awareness that, in London at least, most HIV infected children are of black African origin, ${ }^{3}$ would probably result in more children being identified before they develop symptoms. Early diagnosis of HIV infection is important because it allows children to benefit from interventions such as prophylaxis against opportunistic infections (especially pneumocystis pneumonia), prompt treatment of established infections, parental education, and social support. Early diagnosis may also be associated with a better response to antiretroviral drugs. It is likely that combination antiretroviral therapy will be most effective in children who start treatment before their immune systems are severely damaged.

We thank Dr Angus Nicoll for his help in the preparation of this article.

Contributions: MPR conceived the study, collected and analysed the data, and wrote the first draft of the paper. MS recognised the problem of late diagnosis and supervised the study. Both authors were involved in writing the final version of the paper, and both authors act as guarantors.

Funding: None.

Conflict of interest: None.

1 Department of Health. Guidelines for offering voluntary named HIV antibody testing to women receiving antenatal care. London: Department of Health, 1992 .

2 Centers for Disease Control and Prevention. Revised classification system for human immunodeficiency virus infection in children less than 13 years of age. $M M W R$ 1994;43:1-10.

3 Department of Health. Unlinked anomymous HIV prevalence monitoring programme England and Wales. London: Department of Health, 1996

4 Connor EM, Sperling RS, Gelber R, Kiselev P, Scott G, O'Sullivan MJ, et al. Reduction of maternal-infant transmission of human immunodeficiency virus type 1 with zidovudine treatment. $N$ Engl $J$ Med 1994;331:1173-9.

5 Galli L, de Martino M, Tovo PA, Gabiano C, Zappa M, Giaquinto C, et al Onset of clinical signs in children with HIV-1 perinatal infection. AIDS 1995:9:455-61.

(Accepted 29 July 1997)
See editorial by

Mercey

Department of Sexual Health,

King's Healthcare,

London SE5 9RS

Simon Jones,

senior house officer

Tonya Sadler,

senior house officer

Jan Welch,

consultant in

genitourinary

medicine

continued over

BMJ 1998;316:272-3
The risk of vertical transmission of HIV infection can be reduced by at least two thirds with perinatal interventions, including antiretroviral treatment and abstention from breastfeeding. ${ }^{1}$ The Department of Health recommends offering HIV testing to all pregnant women in areas of high seroprevalence, ${ }^{2}$ but uptake and detection rates remain low, with wide variation between centres. ${ }^{3}$ In 1994-5 only $16 \%(65 / 401)$ of pregnant women infected with HIV in London and south east England were recognised before the birth. ${ }^{4}$ As uptake varies with factors such as the ethnic group of the midwife, ${ }^{5}$ we examined the effect of the midwives' characteristics and site and duration of pre- test discussion on uptake of testing in an area of high seroprevalence. ${ }^{4}$

\section{Subjects and methods}

An antenatal HIV testing programme was introduced in June 1995. All women at their booking visit were offered an HIV test by midwives trained about HIV infection and how to discuss testing. Each midwife was allocated a number (by a senior midwife not involved in the study) and gave details of age, year of qualification, self defined ethnic group, and site of work. For each pregnant woman the midwife's number, 